\section{Animals in Medical Research}

Few topics give rise to such misunderstanding, misrepresentation, and even emotion as the subject of using animals in medical research. It is pertinent, therefore, to consider where scientific developments are leading us in this respect.

In the interests of increasing the speed, accuracy, and sensitivity of assays some modern techniques are doing much to replace animals. Many of the vitamins, which in the beginning were assayed in biological tests, are now so easily synthesized that chemical analysis has replaced the biological assay. Tissue-culture techniques have made great advances in virology. No more than two decades ago infection of susceptible animals was the only means of differentiating one virus from another. Today we learn much from the characteristic cytopathic degeneration caused by viruses in cell cultures, and the neutralization of such activity by specific antiserum characterizes the virus, thus eliminating the use of animals. Indeed there are several viruses that can be detected only in specific cell cultures, and perhaps the most striking example of this is a virus endemic to one species of monkey which can be detected only in the cell cultures of another species of monkey. The most recent developments in the hybridization of viruses have been studied in cell cultures with little use of animals.

Cultures of human cells that can be grown in vitro are well established in public-health work because of their unique sensitivity to some viruses of the upper respiratory tract. The cells are free from contaminating viruses and maintain a normal nuclear structure throughout their life. Thus their suitability is being investigated for the production of virus vaccines, to eliminate the use of animals. Already over 170,000 children in Yugoslavia have been given oral poliomyelitis virus vaccine prepared in these cells, and some 5,000 American Servicemen have been given adenovirus type 4 vaccine similarly prepared.

Diphtheria toxin and antitoxin can be assayed in cell cultures or by haemagglutination techniques, and the concentration of a number of antigens can be measured by geldiffusion, again avoiding the use of animals. Similar trends towards in vitro techniques are evident in fields other than microbiology. For example, in pregnancy tests the use of immature female mice was replaced by South African frogs, and they in turn have given way to the gonadotrophin-coated latex particle.

But despite the development of such a variety of in vitro techniques, it would be a mistake to expect that the overall use of animals will be greatly reduced. Research into the development of a prophylactic for every major disease has been materially advanced by the use of laboratory animals. Even though all these modern techniques were available, the measles virus, isolated and attenuated by Enders and his colleagues, was considered safe for clinical trial in children only when it had failed to infect monkeys. There was no other way of assessing this safety. Again, though American workers have successfully attenuated rubella virus in cell cultures, the decision to test the virus in children was taken only after it was shown that vaccinated monkeys did not excrete the virus and transmit the disease to cage mates.

In biological research outside the field of microbiology there would appear to be many instances when the use of laboratory animals remains imperative. Anaesthetics could not be tested in man without first being exhaustively tested in animals, and many surgical techniques today-for instance, organ grafting-would not be possible without experiments on them. The disastrous effects of thalidomide on the foetus might have been avoided had it been known that inoculation of pregnant rabbits would have shown the teratogenicity of the drug. In fact it is doubtful whether any new drug will now be used in man until adequate data on toxicity and teratogenicity have been obtained from tests on animals. For many reasons research scientists often wish to adopt only in vitro techniques, but the fact remains that most drugs and many operations are made safer for man by prior testing on animals.

\section{New Hypotensive Drug}

Clinical experience with a new hypotensive drug, debrisoquine, is reported this week in the B.M.F. by Drs. A. H. Kitchin and R. W. D. Turner from Edinburgh (page 728) and by Professor W. I. Cranston and his colleagues from Oxford (page 732). The list of hypotensive drugs ever lengthens. What is the need to add a further drug with a straight peripheral sympathetic-blocking action to the ones we already have? Does debrișoquine offer any advantages over others ?

Like guanethidine, bretylium, bethanidine, and methyldopa, debrisoquine selectively blocks the peripheral sympathetic nervous system without antagonizing the effects of endogenously released or injected adrenaline and noradrenaline and without affecting the parasympathetic system. Like these drugs, debrisoquine produces a postural hypotension, which is further exaggerated on exercise. With reduction of blood-pressure goes a liability to dizziness on exercise or sudden movement, and this side-effect, like its others, is a direct result of the pharmacological action.

Compared with guanethidine, debrisoquine seems equally effective in lowering blood-pressure, but like bethanidine it has the advantage of a much shorter duration of action. Tolerance develops, but not so seriously as with bretylium, and control can usually be regained by giving the patient thiazides. The Edinburgh workers found side-effects to be less frequent than with either methyldopa or guanethidine, but this unexpected advantage has yet to be observed in Oxford. Diarrhoea was the most frequent side-effect, and others included tiredness and muscle weakness, nasal stuffiness, and failure of ejaculation, as with the other drugs in this group.

Methyldopa bridged the gap between the useful and less potent combination of thiazides plus low-dosage reserpine and the more potent but less easily regulated guanethidine. While the sympathetic blocking drugs (and this presumably includes debrisoquine) lower blood-pressure by lowering cardiac output, methyldopa also reduces the raised systemic vascular resistance and has more effect on the blood-pressure in recumbency than the other drugs. ${ }^{12}$ This should make methyldopa the preferred choice, but unfortunately it is not always effective in severe hypertension. Moreover, methyldopa frequently causes somnolence and less often pyrexia and even anaemia and jaundice.

1 Kirkendall, W. M., and Wilson, W. R., Amer. F. Cardiol., 1962, 9, 107. 2 Dollery, C. T., Harington, M., and Hodge, J. F., Brit. Heart भ., 1963, 25, 670 .

s Luke, R. G., and Kennedy, A. C. Brit. med. Y., 1964, 1, 27.
Hans, S. F., and Kopelman, H., ibid., 1964, 1, 736.

5 Johnston, A. W., Prichard, B. N. C., and Rosenheim, M. L., Lancet, 1964, 2, 659 . 
After intravenous injection methyldopa's effect is slow, while debrisoquine, like guanethidine, is contraindicated because it causes transient hypertension. So pentolinium still has much to commend it when quick reduction of bloodpressure is needed. The one other remaining use for a ganglion blocker is for combating the diarrhoea caused by a sympathetic-blocking drug.

Because it is said to cause less reduction of renal blood flow methyldopa is probably the drug of choice in hypertension with renal impairment ${ }^{3}$ and also in toxaemia of pregnancy, ${ }^{4}$ as it might be expected to have a more favourable effect on uterine blood flow than the other sympatholytic drugs. While reserpine, guanethidine, and to a less extent methyldopa deplete the myocardial and peripheral vascular stores of catecholamines, bethanidine ${ }^{5}$ and debrisoquine do not have this effect, and they might therefore be selected when there is complicating heart failure. Unfortunately all these drugs can cause retention of fluid, particularly in severe hypertension. Thiazides (or aldactone) both prevent this complication and potentiate the hypotension.

Individual patients vary in their blood-pressure response to pharmacologically similar drugs and their tolerance of sideeffects from them. It is for this reason rather than because it represents a specific advance in therapy that debrisoquine wins a place among the first-line drugs for the treatment of severe hypertension.

\section{Oesophageal Cancer}

The incidence of oesophageal cancer differs widely in different areas of the world. This suggests that environmental factors are of importance in its causation, and because food and beverages come into direct contact with the oesophagus it is tempting to assume that the environmental factors in question are dietary. However, experience in the laboratory with compounds of the nitrosamine class shows that such an assumption is unwise. Specific nitrosamines tend to induce cancer at specific sites, irrespective of the route by which they are administered. A number of agents of this class have been shown to induce oesophageal cancer in laboratory animals. ${ }^{1-3}$ The specificity is so striking-the oesophagus may be the only organ which responds to the carcinogenic effects of a particular compound ${ }^{4}$ - that it is now justifiable to make a direct search of the human environment for nitrosamines which induce oesophageal cancer in man. Obviously, such a search can best begin in a geographical area where oesophageal cancer is prevalent. The observations of the late Dr. R. J. W. Burrell $b^{5}$ suggested that the Transkei region of South Africa may be suitable for this purpose. Here, oesophageal cancer is endemic among the Bantu population; not generally, but in isolated well-defined pockets. In these the morbidity rate for squamous carcinoma of the thoracic oesophagus may exceed 1 per 1,000 of the population each year, whereas in surrounding areas the disease is not seen. In affected persons the presence of carcinoma-in-situ lesions, distinct from the main tumour, suggests that the carcinogenic influence is potent. ${ }^{6}$ In some of these pockets the disease is more or less confined to males, in others to females.

In the Transkei oesophageal cancer has been increasing in incidence, after first becoming prevalent in $1943 .{ }^{5}$ Similar increases in incidence have been observed among the Bantu populations of other regions of South Africa. ${ }^{78}$ White persons and Asians living in the affected areas have not been involved in the increasing incidence of the disease. In the Transkei during the same period there seems to have been a steady falling off in the quality of crops. ${ }^{5}$ The male Bantu tends to spend long periods away from home, and during these periods may be exposed to special cancer hazards. One such hazard is "cidivici," a native beer brewed illicitly, sometimes in metal drums which previously contained petroleum asphalt, and sometimes with the addition of materials such as carbide or metal polish. ${ }^{9}$ Because of the uncontrollable nature of this type of exposure, Burrell and his colleagues confined their most recent study ${ }^{10}$ to persons, mostly women, who had not moved more than a few miles from their homes during the 15 years before death. The gardens of 29 persons who had died from verified oesophageal cancer were compared with those of a similar number who were free of cancer, the expert who examined the gardens being ignorant of the category to which the owner belonged. The "cancer" gardens proved strikingly less productive than the "cancer-free" gardens, and though signs of molybdenum deficiency were seen in all gardens they were more marked in the "cancer" gardens. A third striking finding was that a disease of maize known as "withered end" was seen in all 29 of the "cancer" gardens but in none of the others. Plant injection studies suggested that the crops were affected not solely by shortage of molybdenum but by a complex trace-element deficiency. Nevertheless, it proved possible to reduce the incidence of withered end, and to treble the maize crop, by treating seeds with sodium molybdate solution.

In the light of comments made in the B.M.f. ${ }^{11}$ concerning the significance of the apparent association between the zinc/ copper ratio in soil and cancer of the stomach, ${ }^{12}$ Burrell and his colleagues are careful to point out that any connexion between the agricultural differences in the gardens and the presence or absence of cancer is unlikely to be direct. Nevertheless, their findings command attention for two reasons. First, the differences between the "cancer" and "cancerfree" gardens are very marked, and, secondly, unlike the situation reported by P. Stocks and R. I. Davies ${ }^{12}$ in relation to stomach cancer, the association between the diet of the persons studied and their gardens is very close. Thus persons dependent on gardens with poor yields are more likely to consume less desirable foods such as the prickly vine tips from pumpkins and various edible weeds. A consequence of molybdenum deficiency in maize is a greater susceptibility to fungal infection. It is possible that some fungal toxins are oesophageal carcinogens, though there is no evidence for this at present. The most interesting suggestions made by Burrell and his co-workers refer to the possible effect of molybdenum

\footnotetext{
1 Druckrey, H., Preussmann, R., Schmähl, D., and Müller, M., Neturwissenschaften, 1961, 48, 134.

2 - Ibid., 1962, 49, 19 Steinhoff, D., Beuthner, H., Schneider, H., and Klärner, P., Arzneimittel-Forsch., 1963, 13, 320

- Boyland, E., Roe, F. J. C., Gorrod, J. W., and Mitchley, B. C. V., Brit. f. Cancer, 1964, 18, 265.

${ }^{5}$ Burrell, R. J. W., F. natn. Cancer Inst., 1962, 28, 495.

- Oettlé, A. G., ibid., 1964, 33, 383.

7 Higginson, J., Cancer (Philad.), 1951, 4, 1224.

${ }^{8}$ Jarvis, J. F., E. Afr. med. F., 1953, 30, 523.

- Burrell, R. J. W., S. Afr. med. F., 1957, 31, 401

10 Roach, W. A., and Shadwell, A., F. natn. Cancer Inst., 1966, 36, 201

${ }_{11}$ Brit. med. F., 1965, 1, 1 .

12 Stocks, P., and Davies, R. I., Brit. F. Cancer, 1964, 18, 14

13 Hewitt, E. J., and Jones, E. W., F. Pomologv Hort. Sci., 1947, 23, 254

14 Preussmann, R., Daiber, D., and Hengy, H. A., Nature (Lond.), 1964, 201, 502 .

15 Young, M., and Russell, W. F., Spec. Rep. Ser. med. Res. Coun., 1926.

London.
Wynder, E. L., Bross, I. J., and Feldman, R. M., Cancer (Philad.), 1957, 10,1300 .
} 